\title{
A study of employment outcomes among technical and vocational secondary education graduates in Egypt [Arabic]
}

Salma Nasser

Ali Rashed

Follow this and additional works at: https://knowledgecommons.popcouncil.org/departments_sbsr-pgy

Part of the Demography, Population, and Ecology Commons, Education Commons, Family, Life Course, and Society Commons, and the International Public Health Commons How does access to this work benefit you? Let us know!

\section{Recommended Citation}

Nasser, Salma and Ali Rashed. 2018. "A study of employment outcomes among technical and vocational secondary education graduates in Egypt [Arabic]." Cairo: Population Council. 

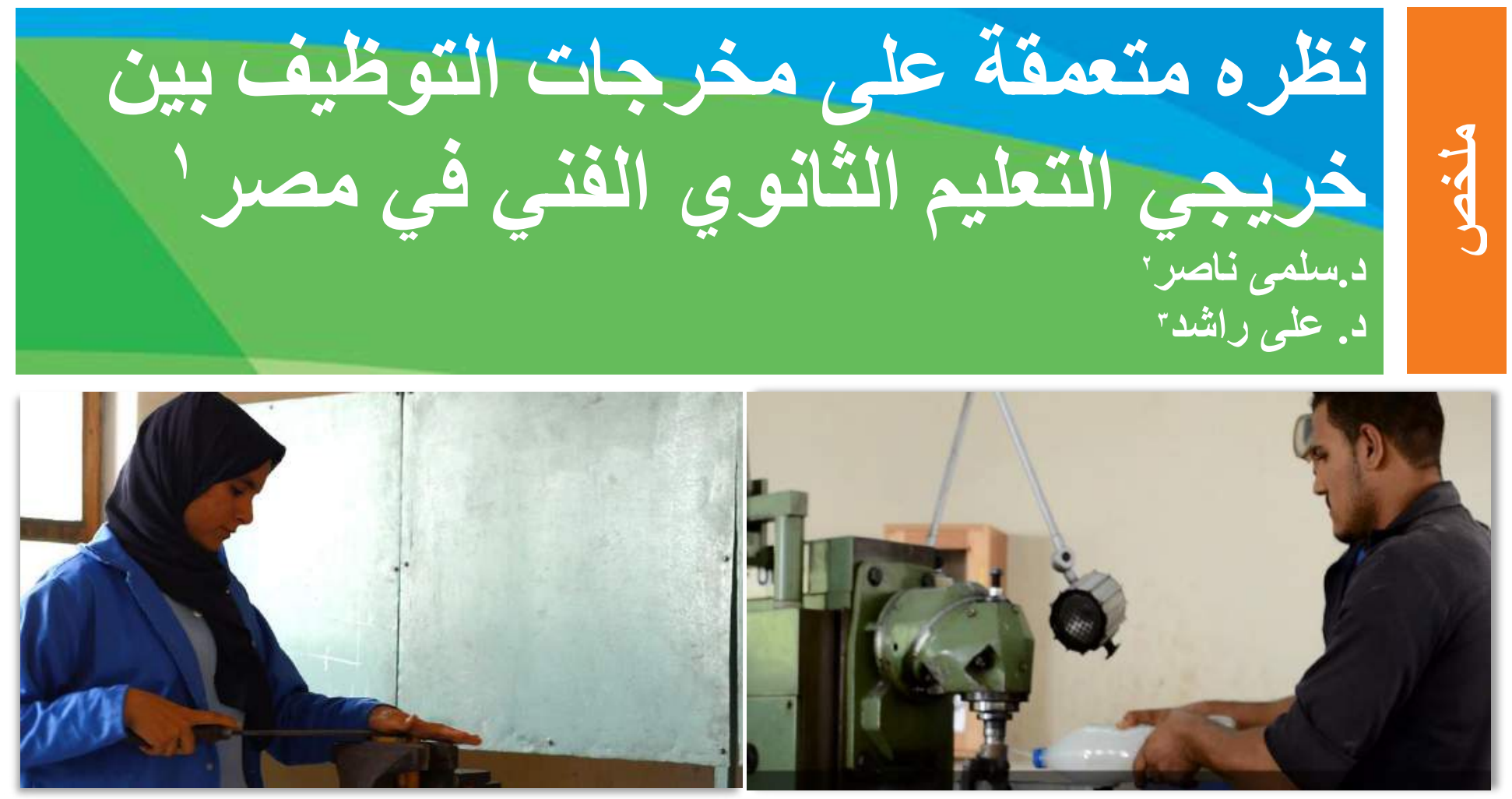

\section{حوالى • ه ؛ ألف طالب وطالبة يتخرجون من التعليم الثانوى الفنى فى مصر سنويا}

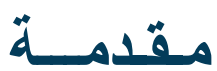

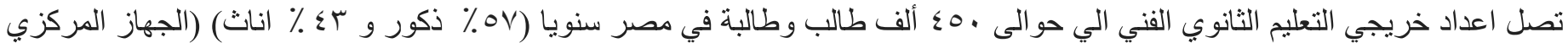

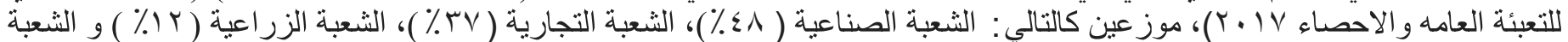

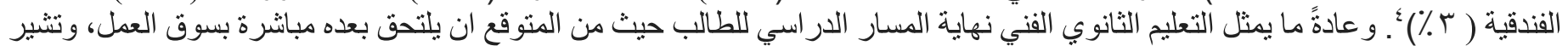

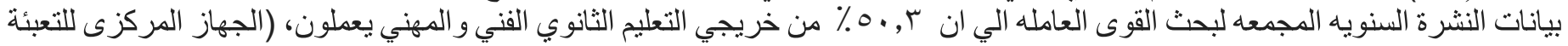

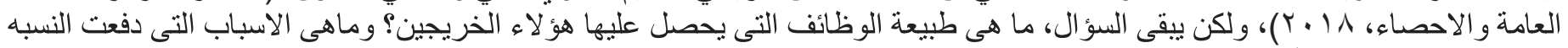

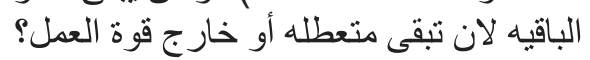

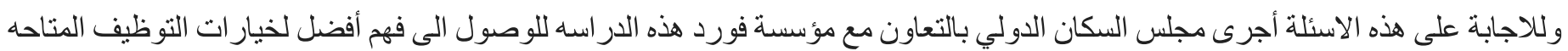

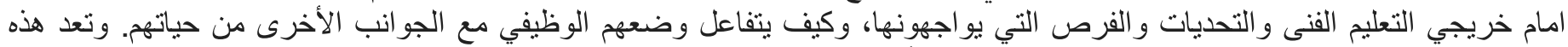

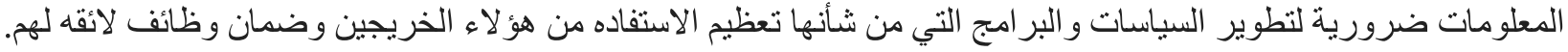

$$
\text { وقد ارتكزت الدراسة على الاهداف التالية: }
$$

• التعرف على مخرجات التوظيف بين خريجي المدارس الثانوية الفنيه و المهنيه وكذللك خصائص الخريجين المرتبطة بتلك المخرجات (مثال

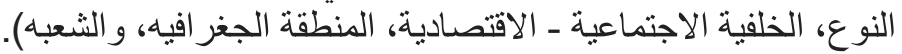

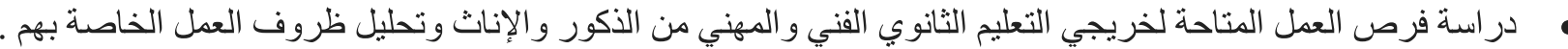

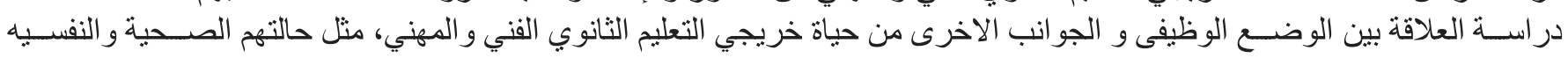

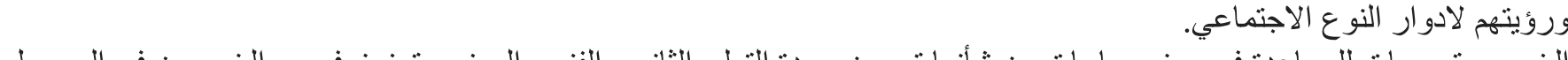
الخروج بثوصيات للمساعدة فى صنّع سياسات من شأنها تحسين جودة التعليم الثانوي الفني و المهني وتعزيز فرص الخريجين فى الحصول على وظائف لائقة.

Nasser, S. and Ali Rashed. (2018, forthcoming). A Study of Employment Outcomes among Technical and Vocational Secondary Education Graduates in Egypt. Final report. Cairo: Population Council

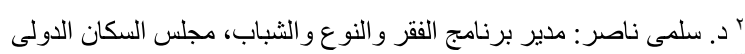

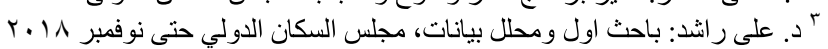

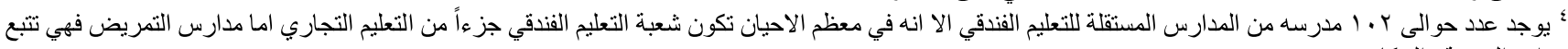

\section{POPULATION} COUNCIL 


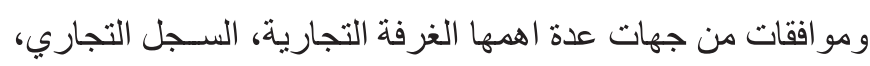

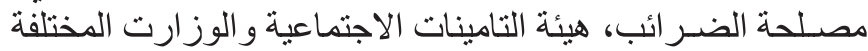

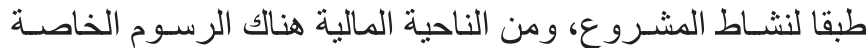

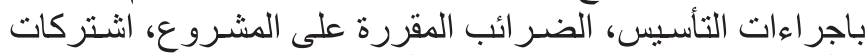

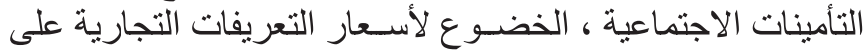

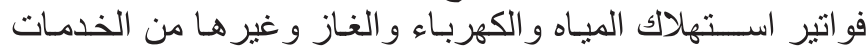

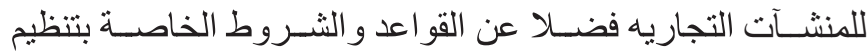

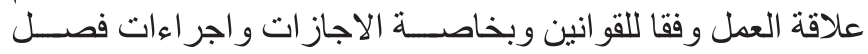

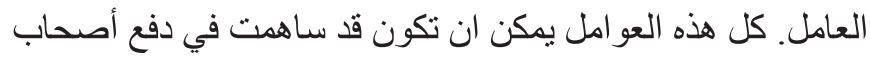

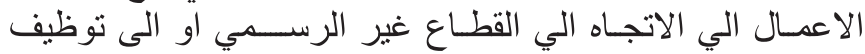

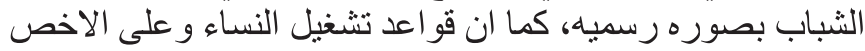

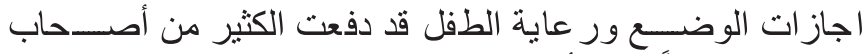

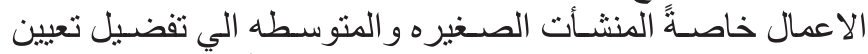
الذكور ، او التحايل على القانون عند تعيين المر أة. وتبقي الاشئــارة

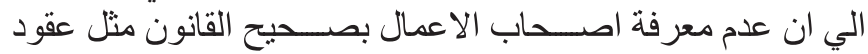

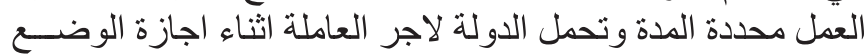

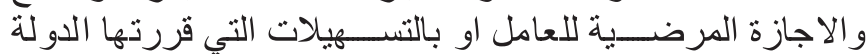

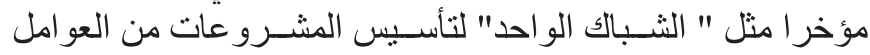

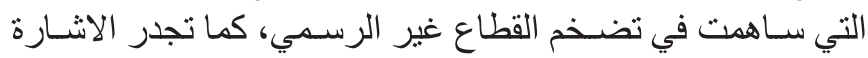

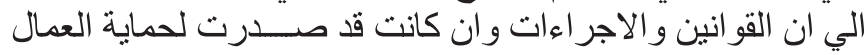

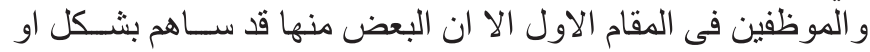

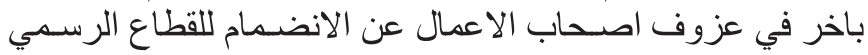

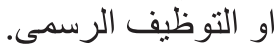

ثُانبا: مخرجـات التوطيف بين خريجي التُطيم الفني والمهني في مصر مخرن

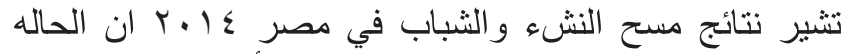

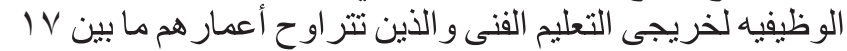

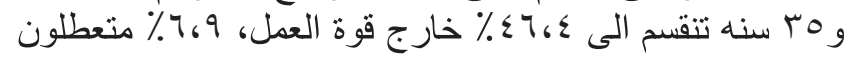

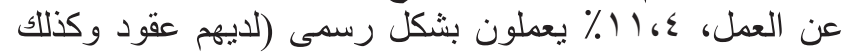

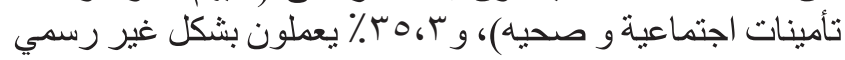

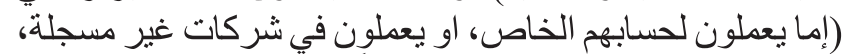

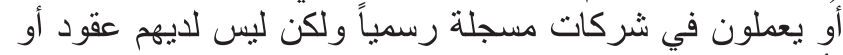

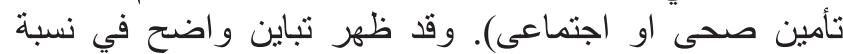

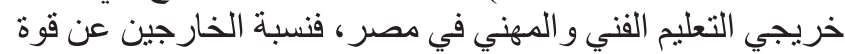

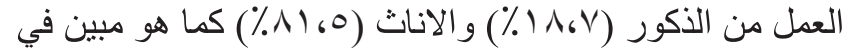

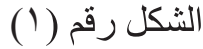

استخدت الدراسة أساليب البحث التالية: (1) مراجعة مكتبية

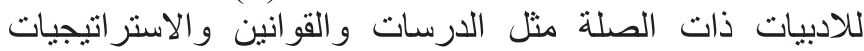

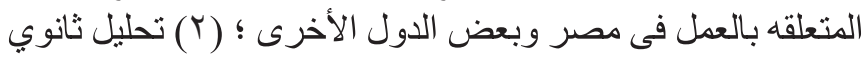
لبيانات مسح النشء و الثباب في مصر (ر انيه رشدى ولئ ومايا سيفردنج

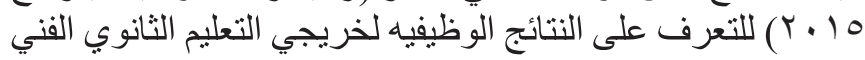

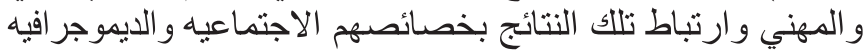

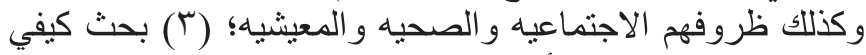

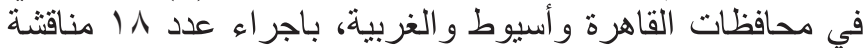

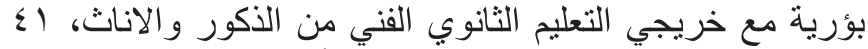

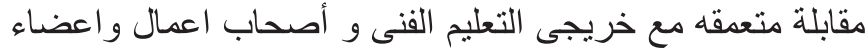
فى مجلس النواب ومسؤولين في وزار اتى التربية و التعليم و القوى اعضي

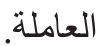

\section{أهم التنائج}

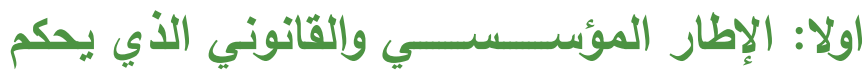
توظيف خريجي التعليم الثثانوي الفني والمهني في مصر

لقد أصبح القطاع غير الرسمي مصدر اً رئيسياً لتوظيف عدد متز ايد التهاي

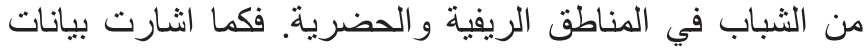

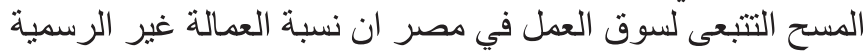

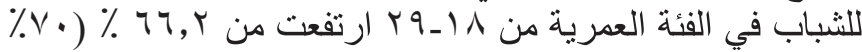

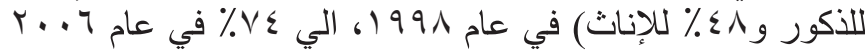

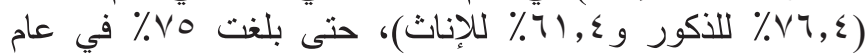

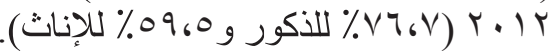

(Economic Research Forum 1998, 2006 and 2012)

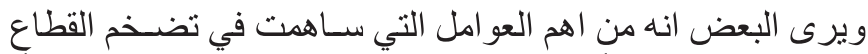

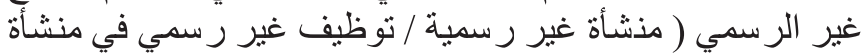

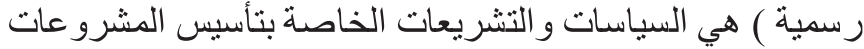

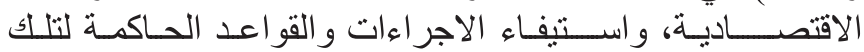

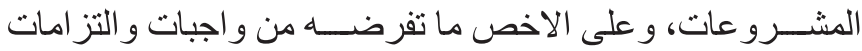

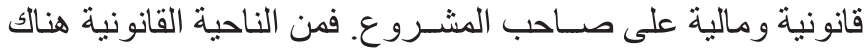

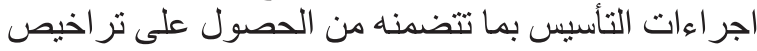

شكل 1: مخرجات التوظيف حسب النوع الاجتماعى (V I _ ه س سنه)
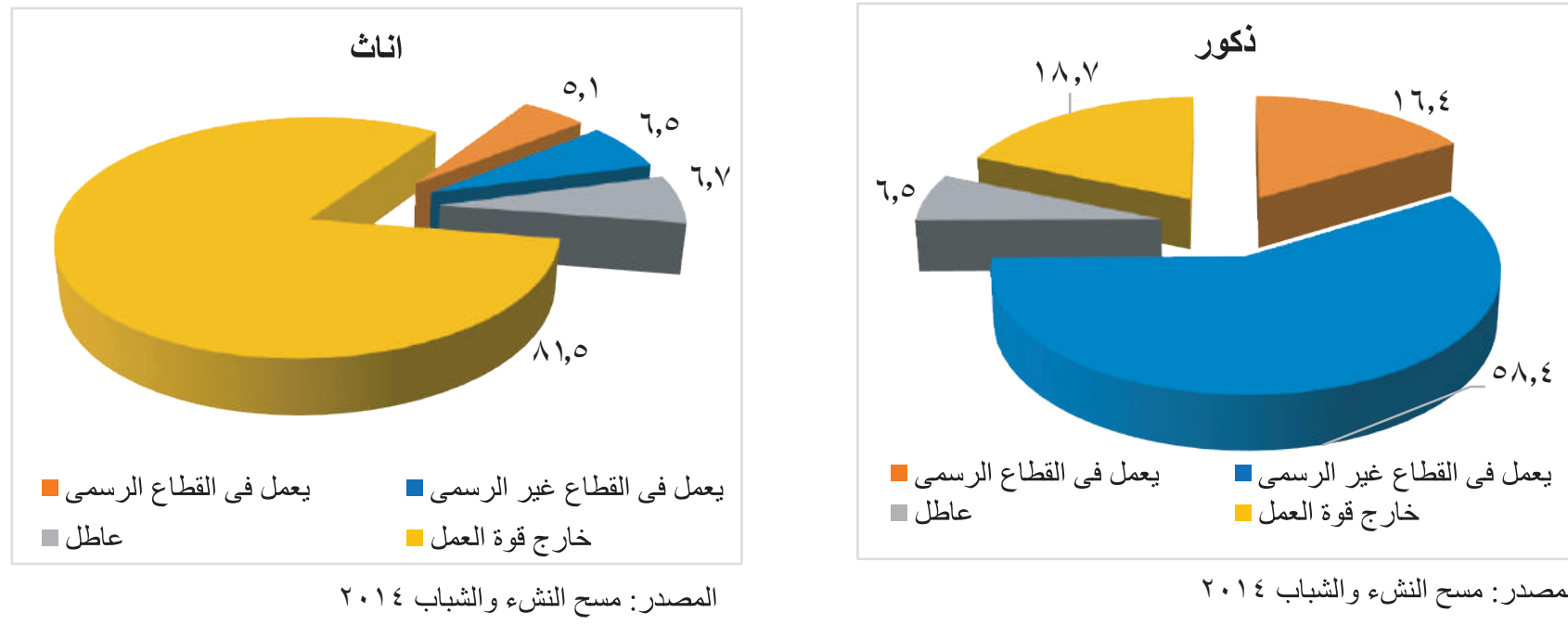

المصدر: مسح النشء و الثباب ع ا •r 


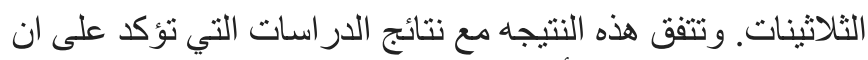

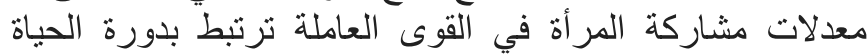
و الانتقال بين رعاية الاسره و العمل. (Mitchell \& Goldin, 2016)

\section{المستّوى الإنّصادى}

ترتفع معدلات البطالة مع ارتفاع مستوى الدخل لخريجي التعليم

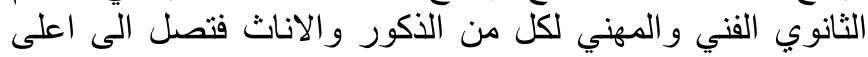

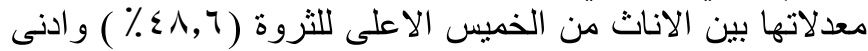

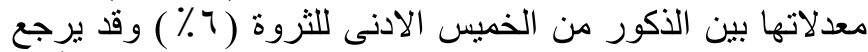

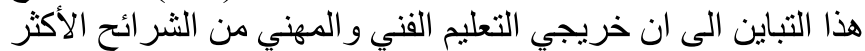

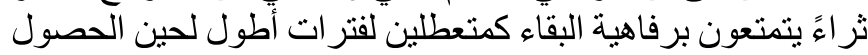

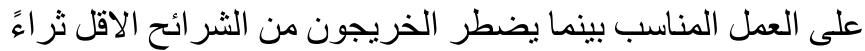
للقبول بما هو متاح من وظائف.

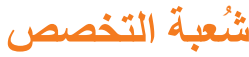

تشير نتائج الدراسه الى ان معدلات المشاركه في قوة العمل بين

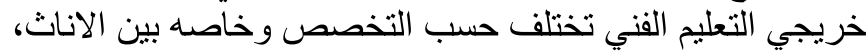
فقد لوحظ ان اعلى معدلات للمشاركه في قوة العمل بين خريجات

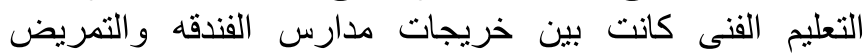

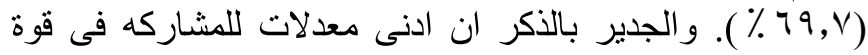

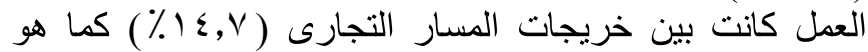

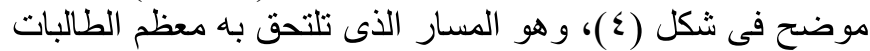

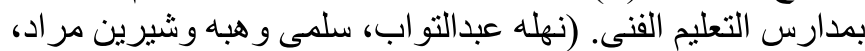

(r.) V
وقد كثـــت المناقثــات البؤرية مع خريجات التعليم الفني و المهني

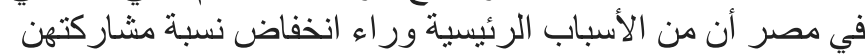

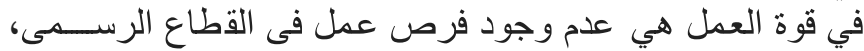

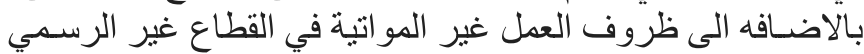

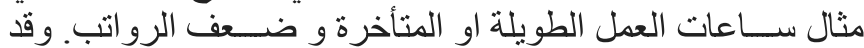

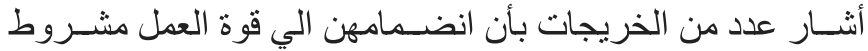

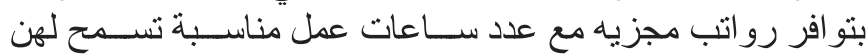
بالتوفيق بين احتياجات العمل وتلبية التزاتئ اماتهن الأسرية.

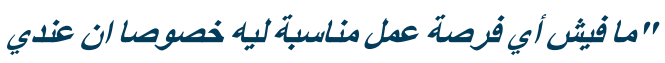

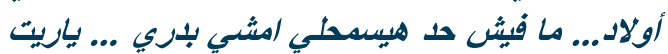

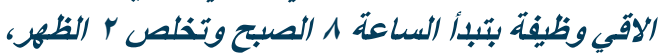
علشان اروح البيت وأخلص اللي وريايا"

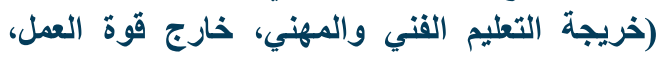
(أسيوط) - (خريجة) - (خ)

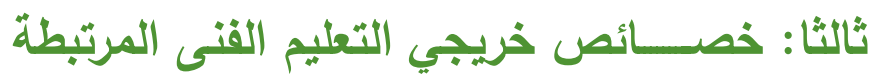
بمخرجات سوق العمل

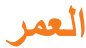

تبلغ نسبة المشاركة فى قوة العمل بين خريجى التعليم الفنى من

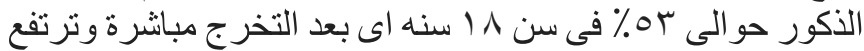

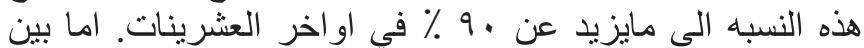

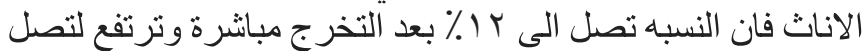

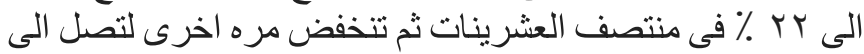

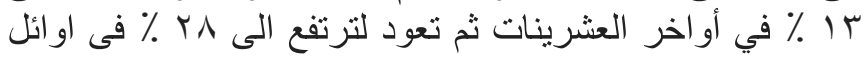
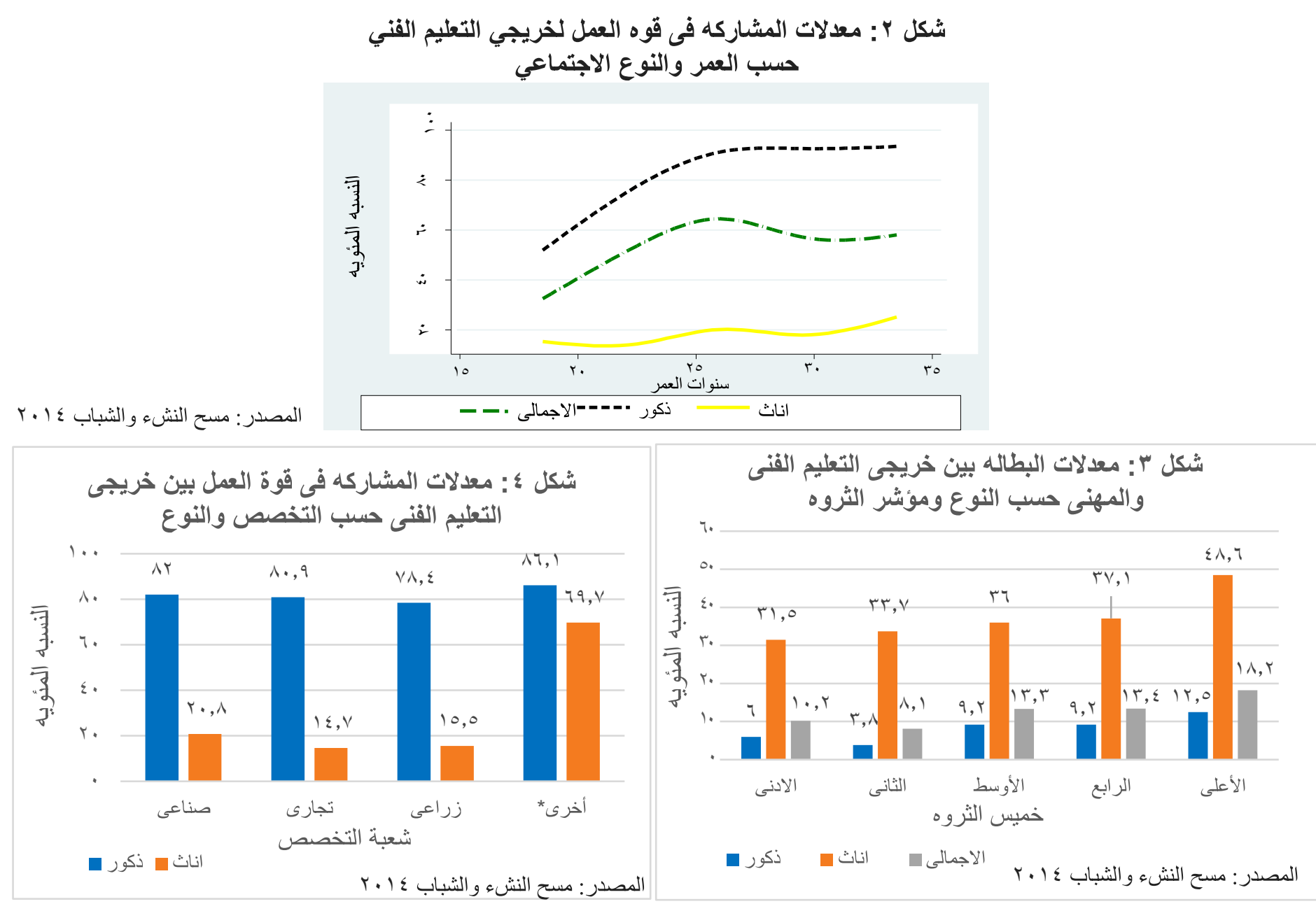

*شمل هذه الفئه خريجى شعبتى الفندقى و التمريض ولنئ 
وقد اتفق معظم المشاركين في الدر اسة على صعوبات متشابهه في

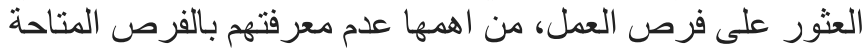

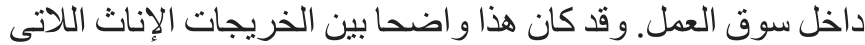

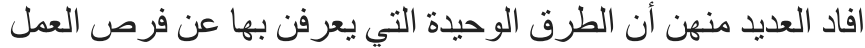

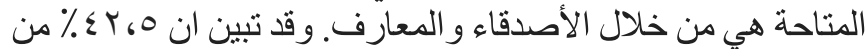

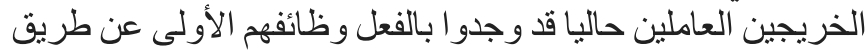

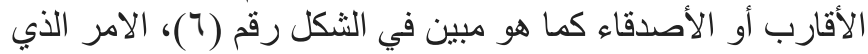

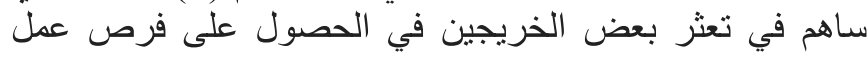
مناسبة لافتقار هم الصلات و العلاقات اللازمة.

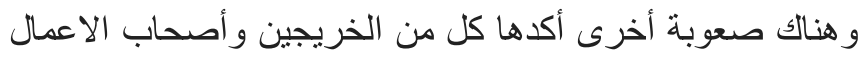

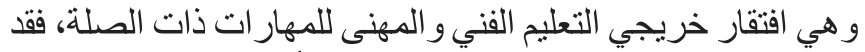

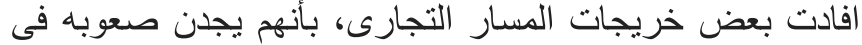

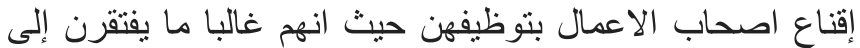

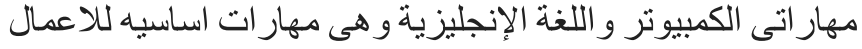

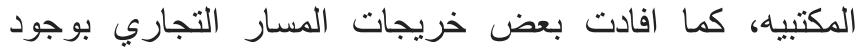
متطلبات متعلقة بالمظهر و التي لا يمكنهن تحمل تكاليفها.

"ملايين معاهم صنايع ومبيعطلوش حاجه بالصنايع واصلا ميعرفش

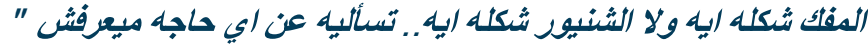
(صاحب مصنع- رسمي- الغربية)
تختلف مخرجات التوظيف حسب المنطقة الجغر افيه، فقد وجد ان

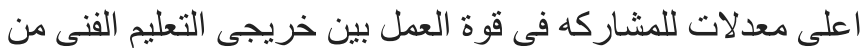

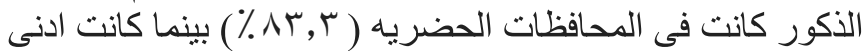

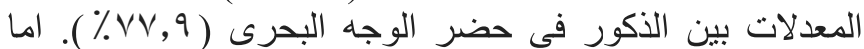

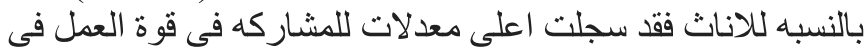

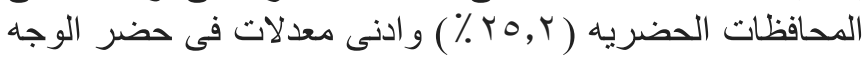

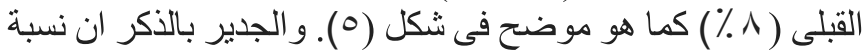

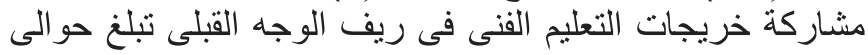

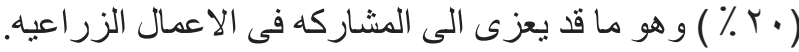

$$
\text { البعا: الانتقال من التعليم الى سوق العمل }
$$

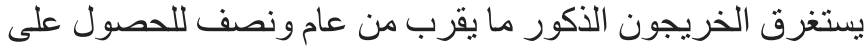

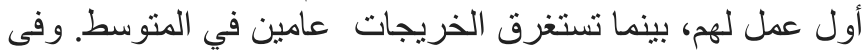

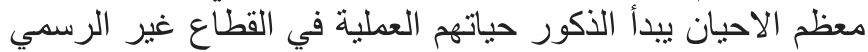

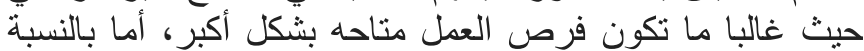

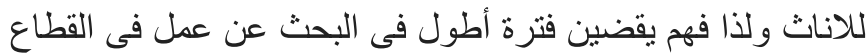

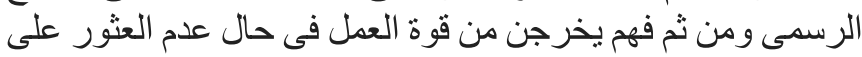

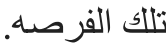

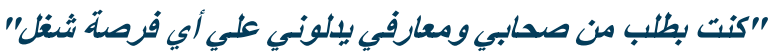

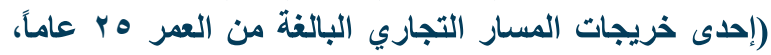
والتي تعمل حالياً كسكرتيرة لأحد المحامين)

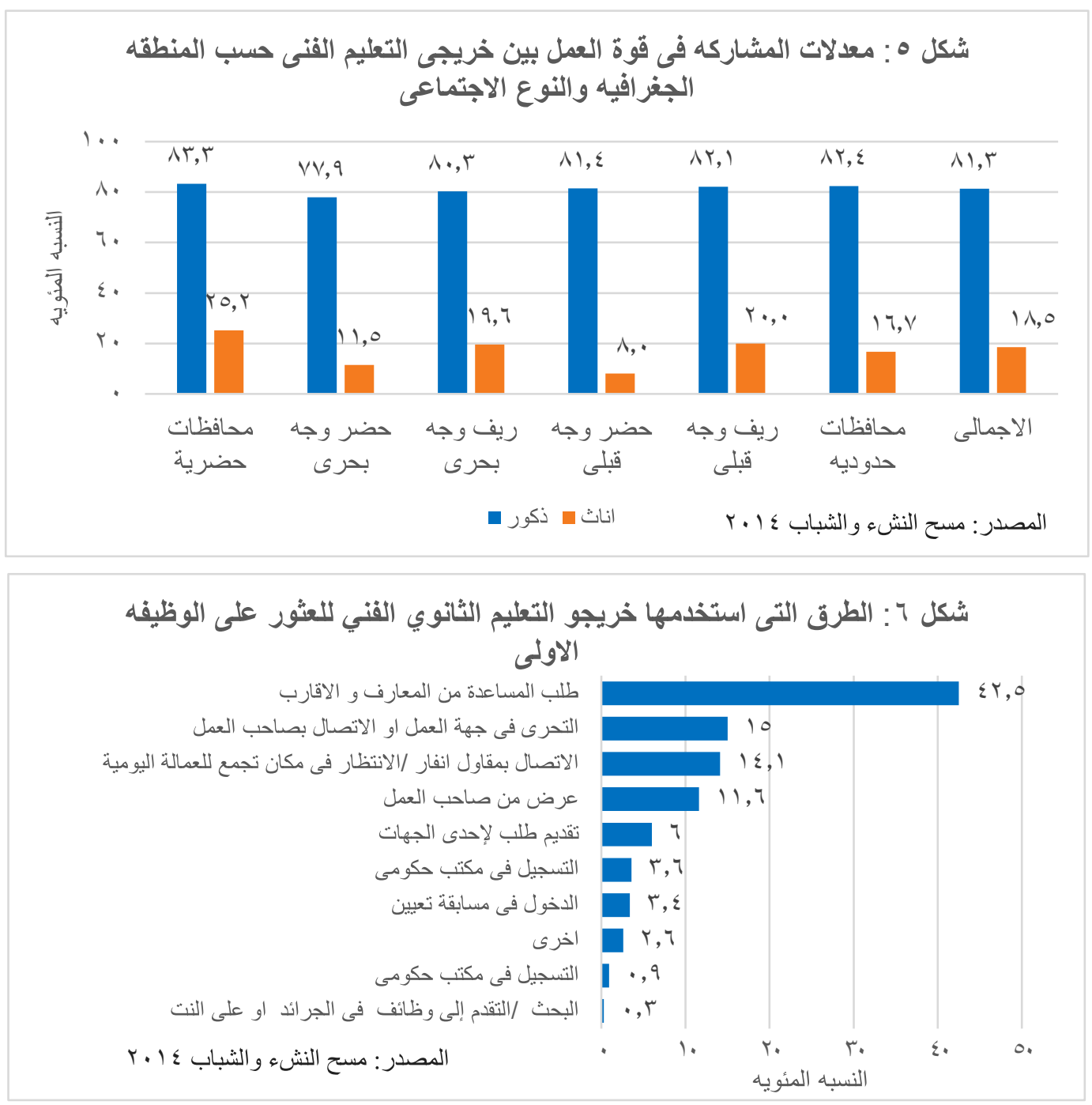




\section{طروف العمل فُي القطاعين الرسمي وغير الرسمي}

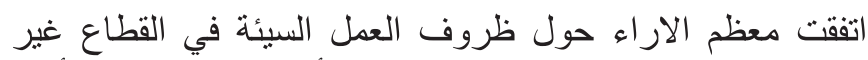
الرسمي. فبالاضافه لغياب عقود عمل يأتي الافتقار إلى الألى الأمان

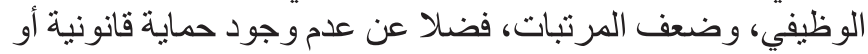
القدرة على الزام اصحاب الاعمال باتباع تدابير السلامة في مكان

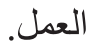
وقد أشار التحليل الثانوي لبيانات مسح النشء و الثباب الى وجود

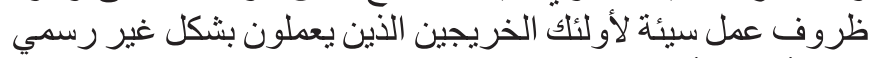

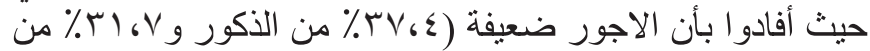

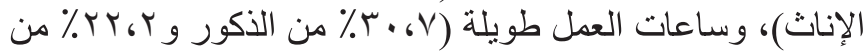

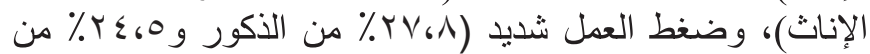

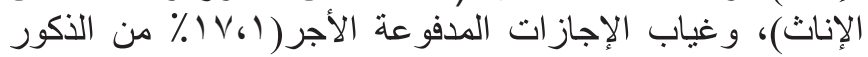

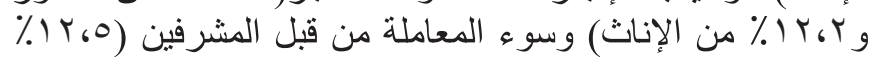

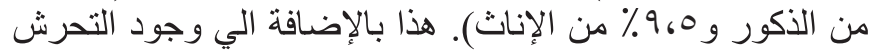

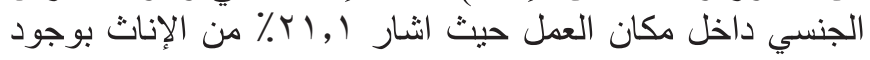

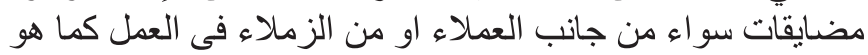

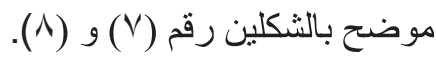

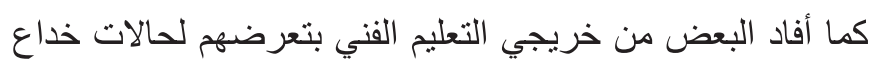

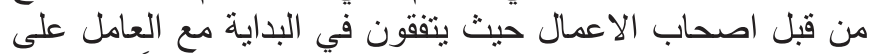
مرتب معين ثم يفاجئونه فى نهاية الثهر بمرتب أقلى فئ كثير أ من المبلغ

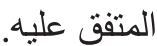

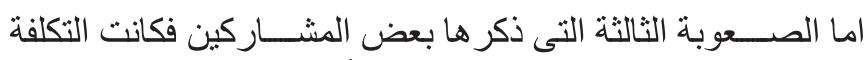

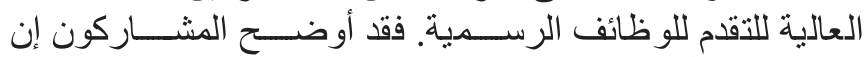

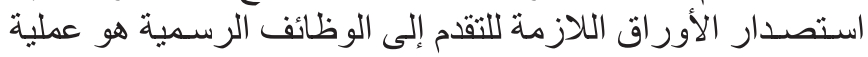

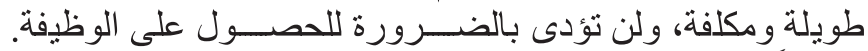

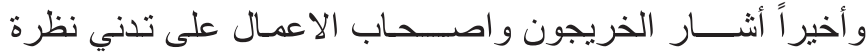

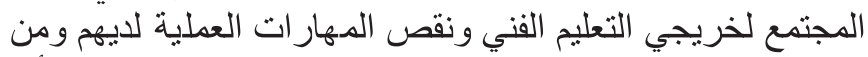

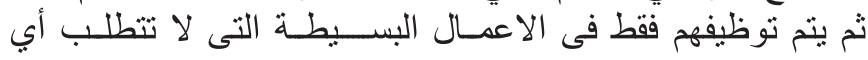

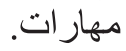

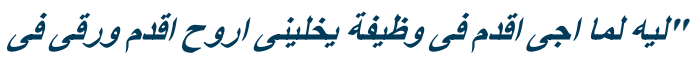

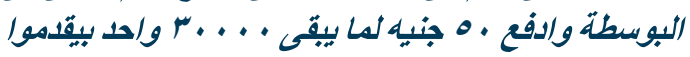

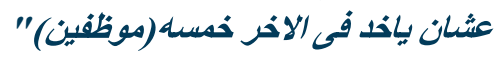

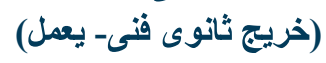

"ارنا شغال فق شركه وكنا بنزل براميل واحنا بنشيل البراميل

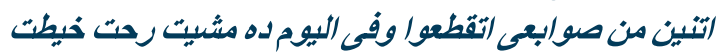

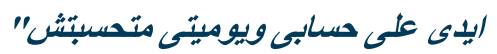
(خريج ثانوى فنى، يعمل فى القطاع غير الرسمى، الغربيه)

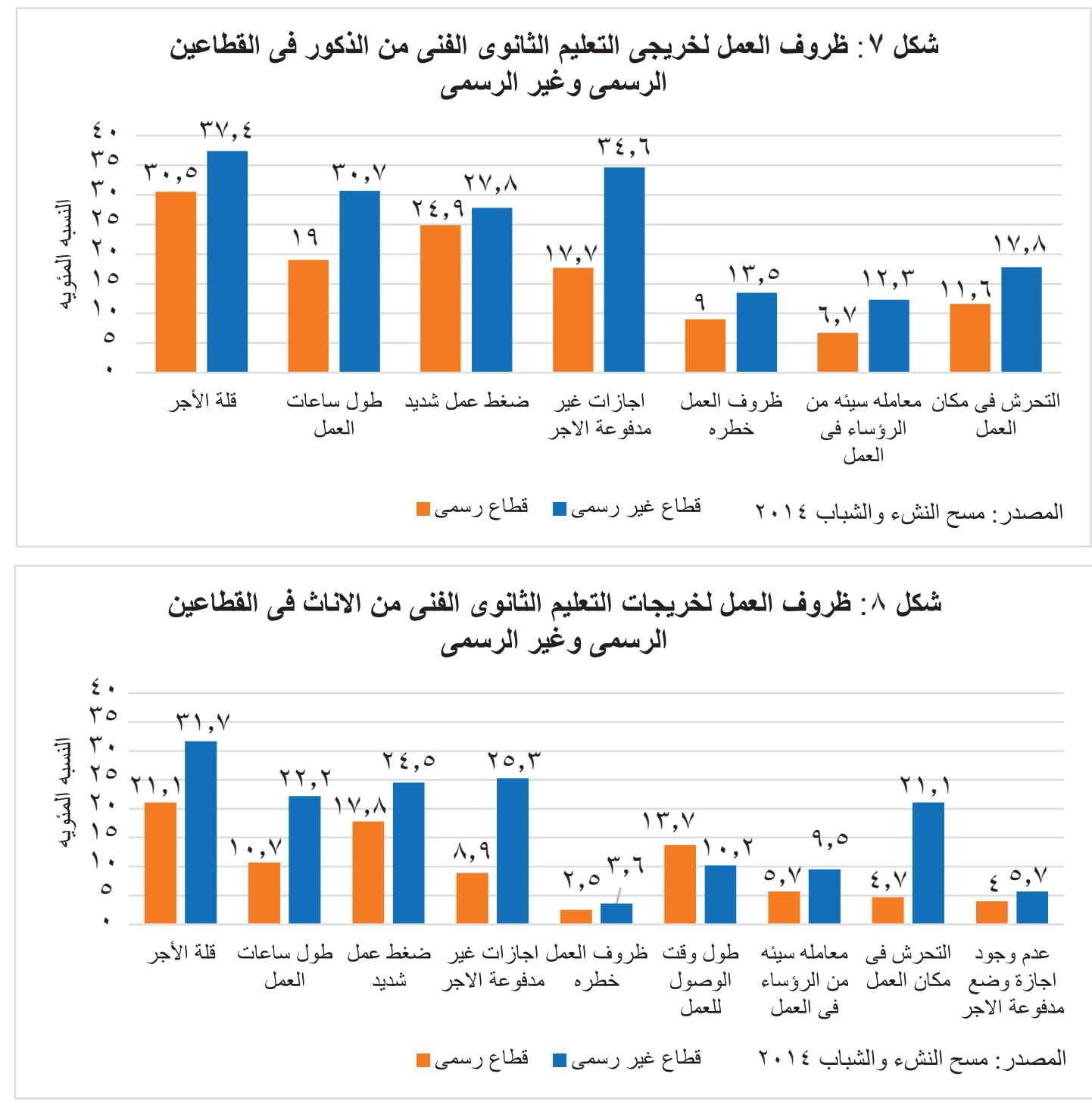




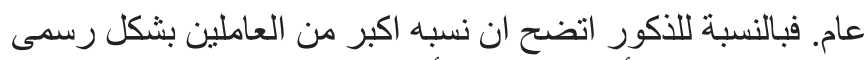

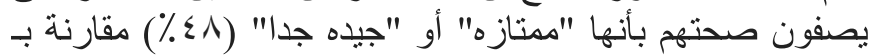

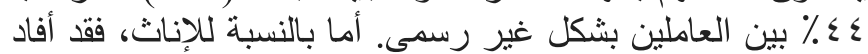

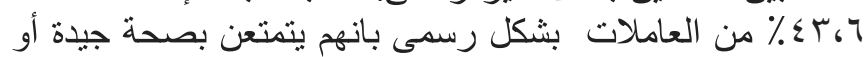

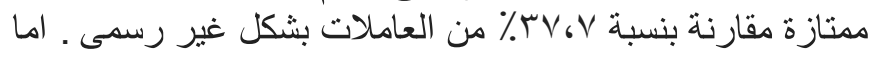

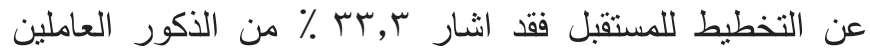

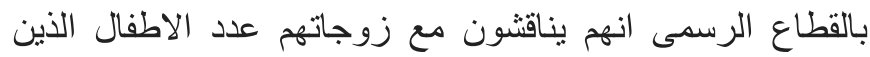

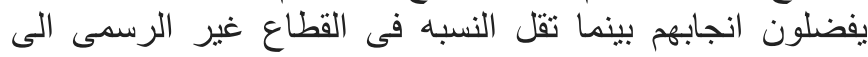

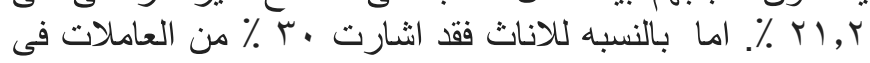

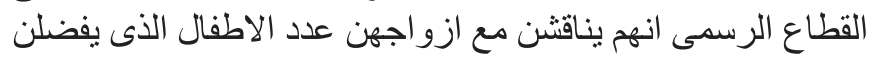

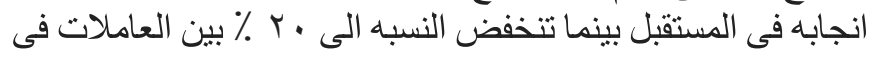

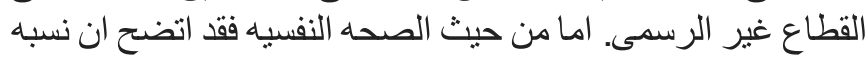

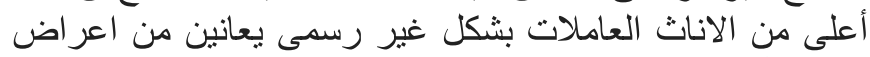

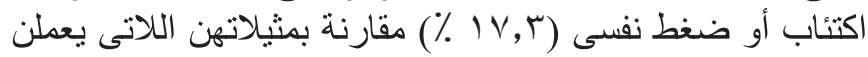
بالقطاع الرسمى (

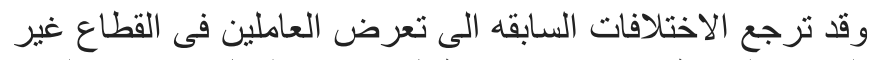

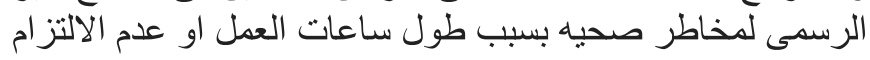

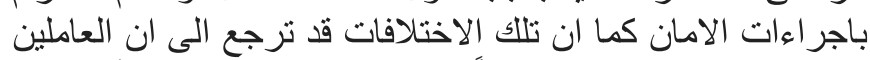

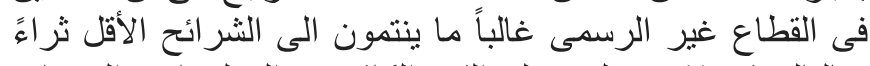

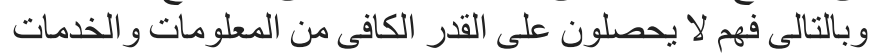

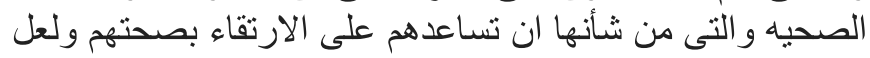

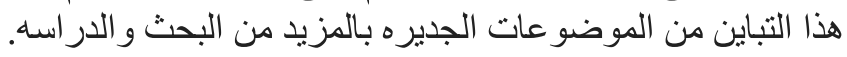

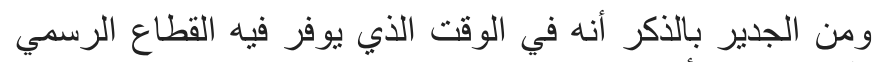

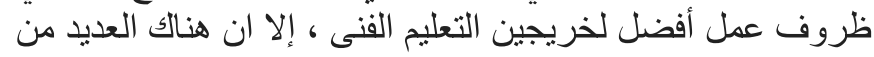

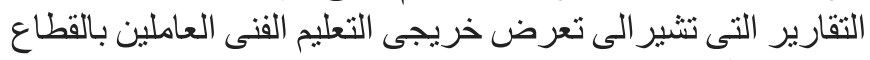

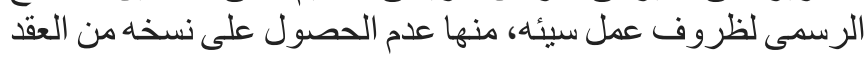

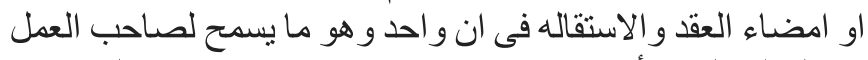

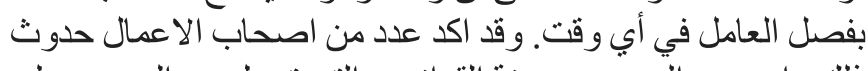

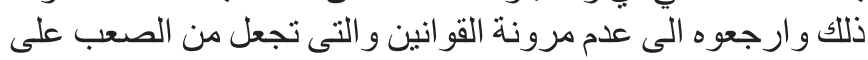
صاحب العمل فصل اي عامل.

وقد اتضح من خلال هذه الدراسه وجود تفال تلفاوت كبير فى الاجور

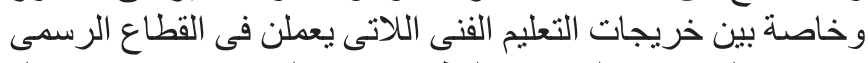

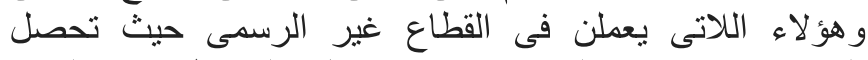

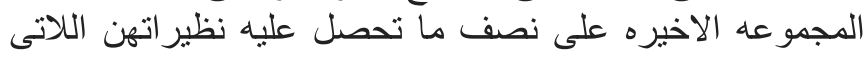

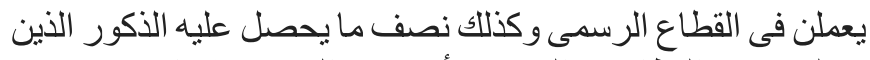

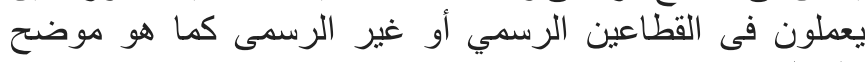

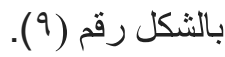

خامسا: ما بعد التّوطّة، العلاقة بين الحالة الوطلئية والنواحي الاخرى لصياة الخربهين تثشير العديد من الدراسات الى وجود صلة بين جودة الوظائف و الجو انب الأخرى لحياة الخريجين، بما في ذلك نو لئة الحياة بشكل
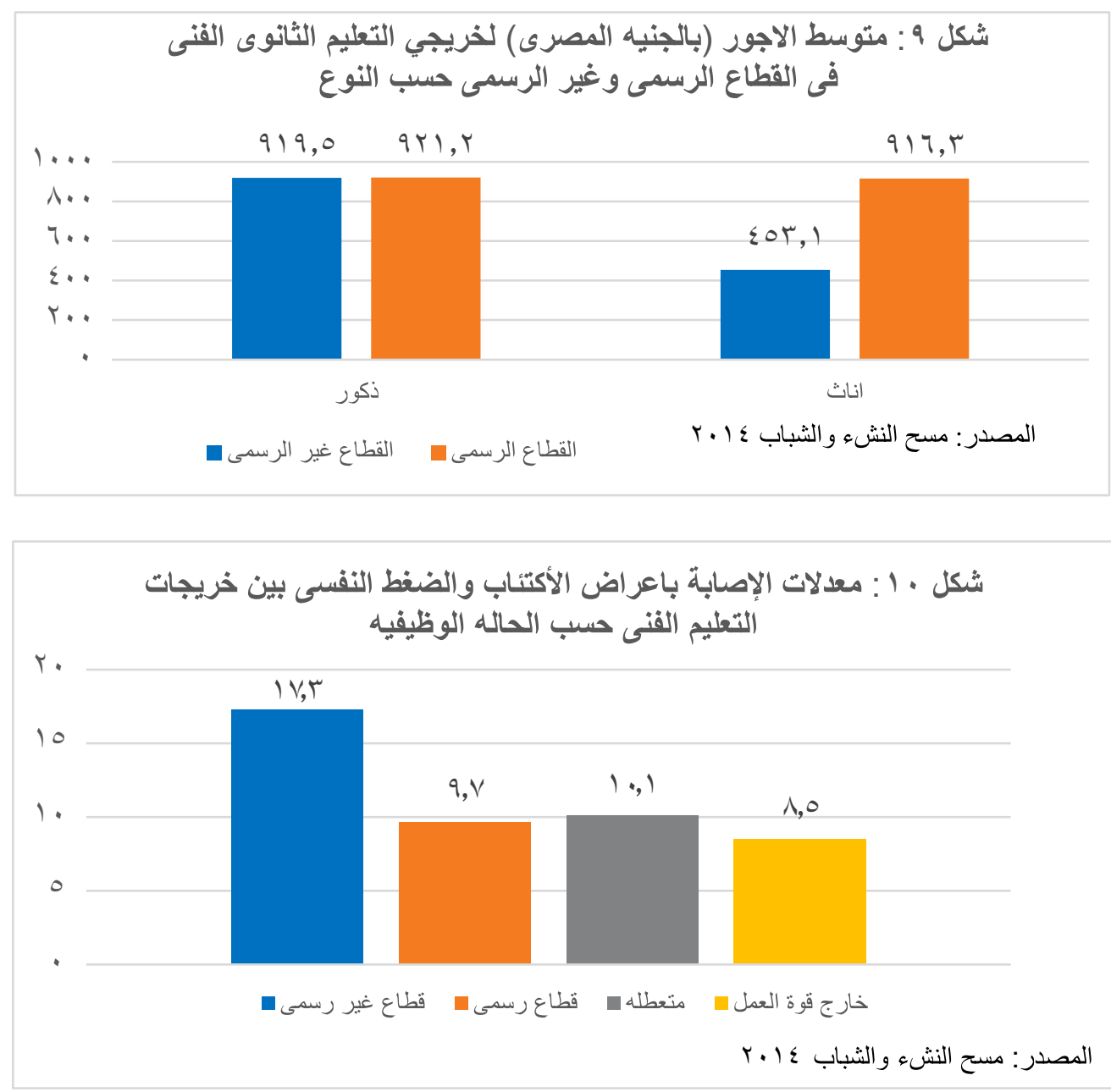


\section{المراج2 - (المر}

\section{المراجع باللغة العربيه}

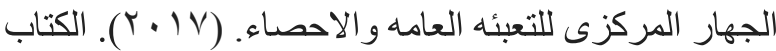
الاحصائى السنوى - التعليه.

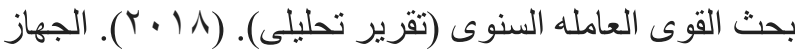
المركزى للتعبئه العامه و الاحصاء.

https://www.capmas.gov.eg/Pages/Publications. aspx?page_id=5104\&Year=2318

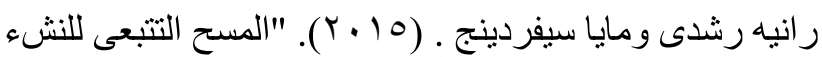

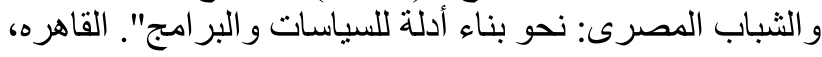

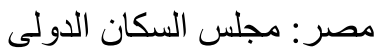

\section{المراجع باللغفه الأنجيزيه}

Economic Research Forum. (1998). Egypt Labor Market Panel Survey. Egypt, Cairo: Economic Research Forum.

Economic Research Forum. (2006). Egypt Labor Market Panel Survey. Egypt, Cairo: Economic Research Forum.

Economic Research Forum. (2012). Egypt Labor Market Panel Survey. Egypt, Cairo: Economic Research Forum.

Goldin, Claudia \& Mitchell, Joshua. (2016). "The New Lifecycle of Women's Employment:

Disappearing Humps, Sagging Middles, Expanding Tops". NBER Working Paper No. 22913

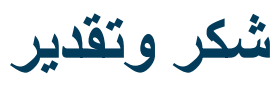

يتقام مجلس السكان الدولي بعظيم الامتنان لكل من ساهم في اجر اء

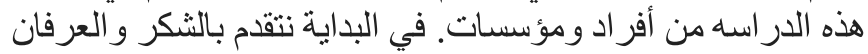

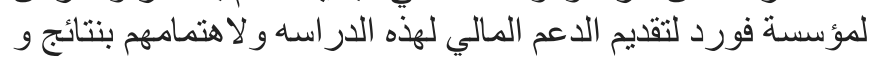

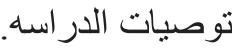

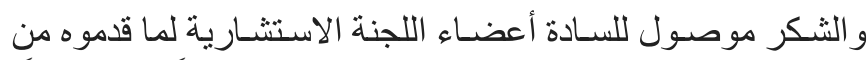

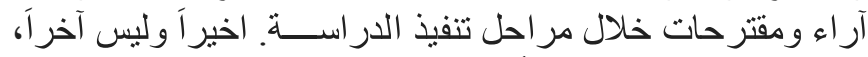

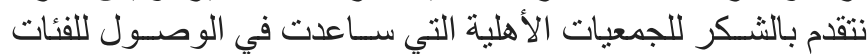
المستهدفة وكذللك خريجي التعليم الفني و الخبر اء و وأصحاب الإلئ الأعمال

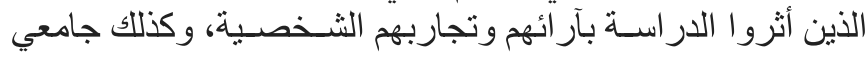

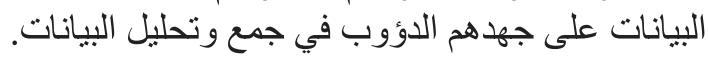

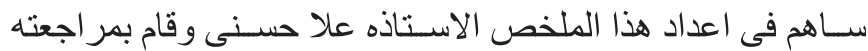
د.نهله عبد التواب و أ.طارق علم الدين وقام باخر اجه أ.مونيكا ماهر الهر

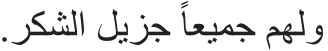

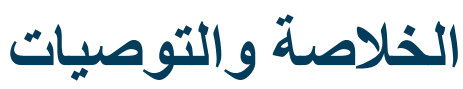

يلقي هذا البحث الضوء على الواقع الوظيفى لخريجي التعليم الفني

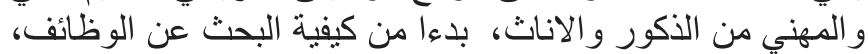

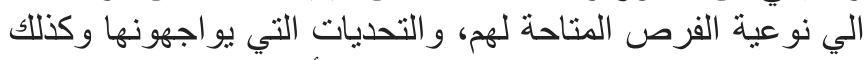

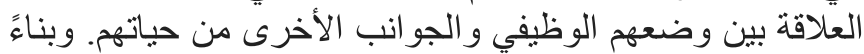

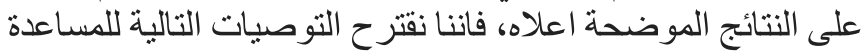
على تحسين مخرجات سوق العمل لخريجي التعليم الفني و المهني التياتي مما يسمح لهم بتحقيق طموحاتهم و الاستفاده الكامله من قدر اتهم.

ـ تحسـين ظروف العمل للعاملين بشــكل غير رســي من خلال

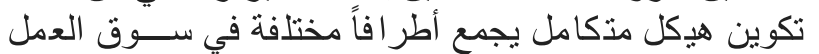

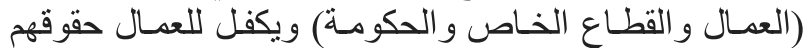

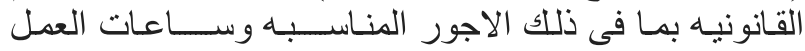

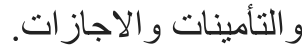

- توسـيع نطاق بر امج الحماية الاقتصـادية ــ على سـبيل المثال

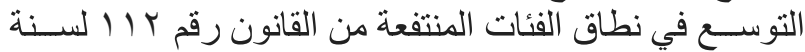

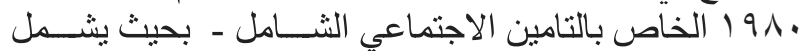

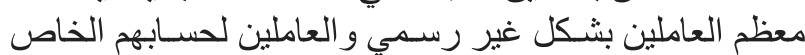

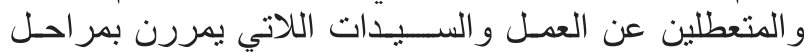

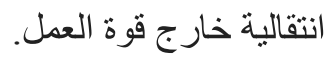

- توفير بيئة عمل صديقة للأسرة من أجل مساعدة السيدات على فلى العاعل

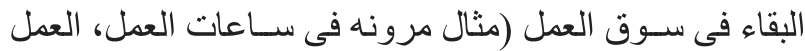

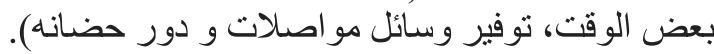

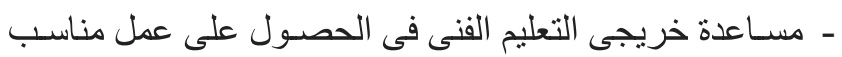

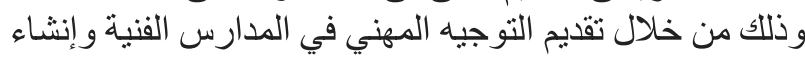

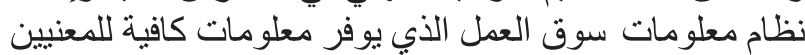

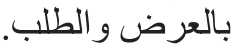

- تشـيع اصـاب الاعمال في القطاع غير الرســي للانضـمام

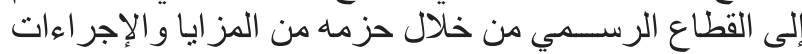
المبسطه

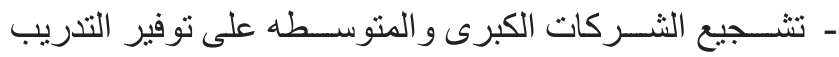
العملي للخرجين وطلاب المدارس الفنية من خلال حز مه من لتصن

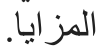

- تعزيز مخرجات التعليم الفني من خلال تحســين جودة التعليم

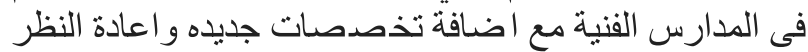
فى التخصصات التى لا تلقى طلبا فى سوق العمل.

ـ تغيير نظرة المجتمع لخريجي التعليم الفني لتكون اكثر ايجابيه

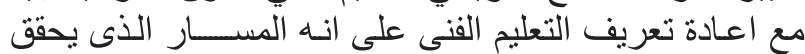

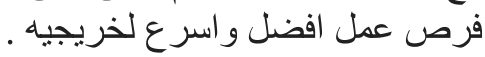




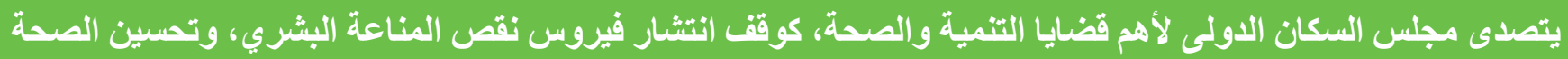

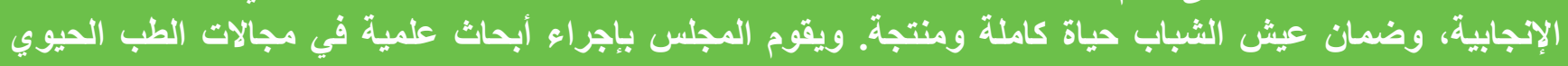

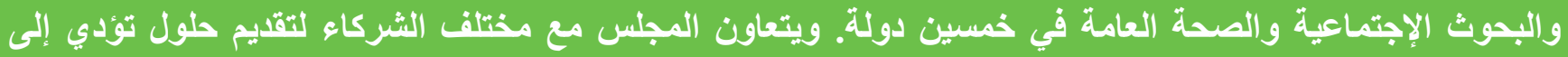

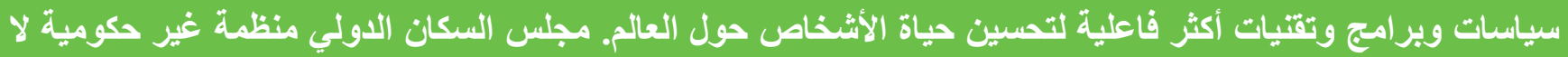

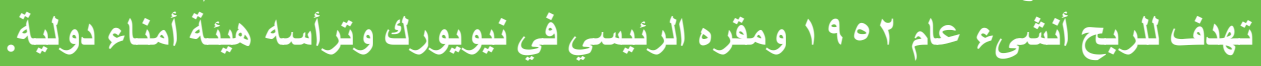

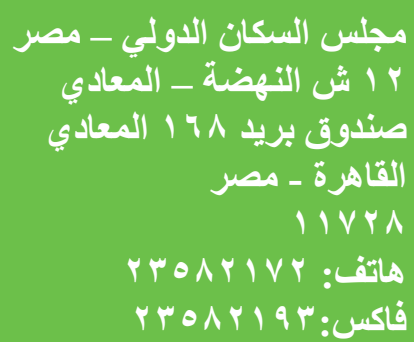

www.popcouncil.org الموقع الاكتروني:

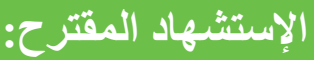

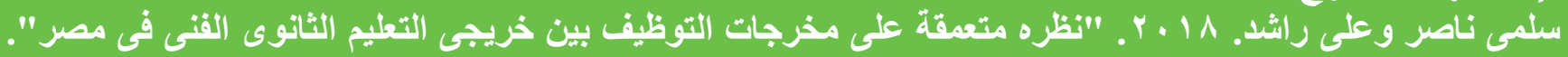

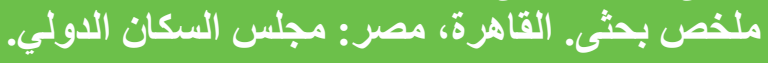

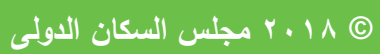

\section{POPULATION COUNCIL}

Ideas. Evidence. Impact. 